
of this work in other works

\title{
Adaptive Static Line Rating for Systems with HTLS Conductors
}

\author{
I. Albizu, Member, IEEE, E. Fernandez, Member, IEEE, R. Alberdi, M. T. Bedialauneta, and A. J. \\ Mazon, Member, IEEE
}

\begin{abstract}
Operation and planning of a power system are constrained by the rating of power lines. Usually, the static line rating is used for system operation and planning. The static line rating defined for an electric grid uses the same conservative weather assumptions for the whole grid regardless of the location of each line or its maximum-allowable conductor temperature. A separate analysis of the weather magnitudes measured in a pilot line shows how favorable air temperature and solar heating compensate for unfavorable wind speed. However, this compensation is limited for high maximumallowable conductor temperatures. As a result, the risk of the static line rating exceeding this maximum temperature is higher for HTLS conductors. An adaptive static line rating is proposed to control the assumed risk. The wind speed assumption for the static rating is reduced for higher maximum-allowable conductor temperature.
\end{abstract}

Index Terms-Transmission line, static line rating, ampacity, overhead line, high temperature low sag HTLS conductor, power system operation, power system expansion planning.

\section{INTRODUCTION}

$\mathrm{O}$ verhead lines are exposed to variable weather conditions that affect their rating. This rating is limited by the maximum-allowable conductor temperature (MACT) of conductors. The reason for this temperature limit is related either to clearance limitations or to conductor annealing. The conductor temperature that results from line operation should never go over the MACT. This conductor temperature depends on the weather conditions. With conditions, such as high cooling because of high wind or low air temperature, conductor temperature is lower, and vice versa. Therefore, the line rating is variable. To make the most of the line currentcarrying capability, dynamic line rating (DLR) monitoring systems have been developed. These systems measure weather magnitudes in the vicinity of the line, or direct magnitudes such as conductor temperature, tension or sag [1], [2]. Several utilities are trying to implement these systems for

This study is financially supported by the Ministerio de Economía, Industria $\mathrm{y}$ Competitividad, under the project DPI2016-77215-R (AEI/FEDER, UE), and by the University of the Basque Country UPV/EHU under the project EHU16/19.

I. Albizu, E. Fernandez, R. Alberdi, M. T. Bedialauneta, and A. J. Mazon are with the Department of Electrical Engineering, University of the Basque Country UPV/EHU, Alda. Urquijo s/n, 48013, Bilbao, Spain (e-mail: igor.albizu@ehu.eus;elvira.fernandezh@ehu.eus;ralberdi004@ikasle.ehu.eus; miren.bedialauneta@ehu.eus; javier.mazon@ehu.eus). grid operation [3], [4]. DLR monitoring systems provide information about the current state of lines, but grid operation requires predictions of the grid condition several hours in advance. This is why DLR forecasting methods are being developed [5], [6].

In contrast to DLR monitoring, utilities traditionally have used the static line rating (SLR), a fixed rating system based on conservative weather conditions of low perpendicular wind speed (e.g., $0.6 \mathrm{~m} / \mathrm{s}$ ), a high air temperature (e.g., $30{ }^{\circ} \mathrm{C}$ ) and full solar heating (e.g., $1000 \mathrm{~W} / \mathrm{m}^{2}$ ) [7]. The SLR method has some limitations compared to DLR monitoring systems with regard to the use of the actual rating of the line. However, SLR has some important advantages as it does not require the installation of monitoring systems, it is secure, and it is easy to implement in wide areas of the grid. The assumed weather conditions are conservative but they do not provide a total protection because the actual wind speed is sometimes lower than the assumed value, or the air temperature and the solar radiation are higher [8]. However, the probability of this happening is low. According to [9], for the static rating, "the highest local conductor temperature will not exceed the maximum design temperature by more than $20^{\circ} \mathrm{C}$ when the line current equals the line rating. The average temperature of a line section will not exceed the maximum design temperature by more than $10{ }^{\circ} \mathrm{C}$ even under exceptional situations and will provide a confidence level of at least $99 \%$ that the conductor temperature will be less than the design temperature when the line current equals the line rating”. Power system operation is usually limited by the static rating of power lines.

The replacement of conductors by high temperature low sag (HTLS) conductors allows secure and safe increase of line power flow without having to strengthen the transmission towers [10]-[14]. The MACT for these conductors is higher than for conventional conductors.

In an electric grid, the same assumed weather conditions are applied to all sizes and types of conductors regardless of the location of each line or its MACT [15]. However, the application of weather assumptions designed for conventional conductors of low MACT (e.g., $50{ }^{\circ} \mathrm{C}$ ), to high temperature low sag (HTLS) conductors with higher MACT (e.g., $150{ }^{\circ} \mathrm{C}$ ) results in a lower confidence level and higher temperature exceedance.

This article analyzes the effect of MACT in the security of the static rating. For this purpose, the weather magnitudes measured in a pilot line are used. In addition, an adaptive 
static rating method for system operation and planning that improves the security level for higher MACTs is developed.

\section{SECURITY OF THE StATIC RATING AS A FUNCTION OF THE MACT}

The security problem arises when the actual cooling of a line is lower than the cooling assumed for the rating. When the three weather magnitudes are favorable (actual wind speed higher than the value for the static limit, air temperature lower than the limit value and solar heating lower than the limit value), the static rating is secure. In this case, if the line current equals the static rating, the conductor temperature does not exceed the MACT. On the contrary, when all the three magnitudes are unfavorable, the static rating is unsecure. In this case, if the line current intensity equals the static rating, the conductor temperature exceeds the MACT. Fortunately, the probability of occurrence of the latter case is low because high air temperature and solar radiation do not correlate with low wind speed.

However, although some weather magnitudes are favorable, others can be unfavorable. This situation is quite common. The most common situations are those with unfavorable low wind speed, lower than the limit value, and favorable air temperature and solar radiation, lower than the limit value. In this case, the cooling can be favorable or not, depending on the particular values and their effects. Sometimes, low air temperature and solar heating can compensate for low wind speed resulting in favorable cooling, whereas at other times, the effect of low wind speed is stronger, resulting in unfavorable cooling.

This is related to the diurnal cycle of the weather magnitudes. During the day, air temperature and solar radiation rise up to a maximum around midday, and wind speed increases as well. At night, wind speed decreases, and values of air temperature, and obviously solar radiation, drop too. Therefore, most low wind periods occur at night.

The thermal balance result is the key for the security of the line. Several studies have been carried out to model the thermal balance of overhead conductors [16]-[24]. The steady state thermal balance of an overhead conductor is defined by Eq. (1), where $P_{J}$ is the Joule heating term, $P_{S}$ solar heating, $\mathrm{P}_{\mathrm{C}}$ convective cooling, and $\mathrm{P}_{\mathrm{R}}$ radiative cooling [17].

$$
P_{J}+P_{S}=P_{C}+P_{R}
$$

The cooling effect of the weather magnitudes depends on the conductor temperature. The effect of the wind speed in the cooling of conductors is stronger than the effect of the air temperature and solar radiation at high conductor temperatures. As a result, when the MACT is higher, and air temperature and solar heating are favorable but wind speed is unfavorable, the compensation effect of air temperature and solar heating is smaller, and, more frequently, the resulting cooling is unfavorable. Consequently, the security of the static rating decreases.

\section{A. Method for quantifying separately the effect of each weather magnitude}

To quantify separately the effect of each weather magnitude, a procedure is defined.

Firstly, the static solar radiation is substituted by the measured value and the ampacity is calculated, that is, the static air temperature and wind speed are maintained but the solar radiation is changed.

Secondly, the static air temperature is substituted by the measured value, that is, the static wind speed is maintained but the solar radiation and air temperature are changed. Therefore, by comparing the ampacity of the second change (solar + air temperature) with the first change (solar), the effect of the air temperature is quantified.

Thirdly, the wind speed is substituted by the measured value and the ampacity is calculated. In this case, all the weather magnitudes are the measured ones. Therefore, comparing the ampacity of the third change (solar + air temperature + wind speed) with the second change (solar + air temperature), the effect of the wind speed is quantified.

The thermal balance equations used for the calculation of the ampacity are those defined in CIGRE 601 [17].

\section{B. Pilot line}

To quantify this effect, the weather magnitudes measured in a $30-\mathrm{kV}$ pilot distribution line in Spain are used (Fig. 1). The wind speed is measured with an ultrasonic anemometer installed on a transmission tower at $10 \mathrm{~m}$ above ground. The solar radiation and air temperature sensors are located at $4 \mathrm{~m}$ above ground. Measurements are taken every minute from July 2010 to June 2013. The line conductors are ACSR of LA-180 type, with a diameter of $17.5 \mathrm{~mm}$.

The latitude of the tower where the monitoring system is located is $43,21^{\circ}$ and the longitude $-02,41^{\circ}$. It is $120 \mathrm{~m}$ above sea level. The Cantabrian Sea is at a distance of $15 \mathrm{~km}$. The terrain is composed of hills and some small woods.

The assumed weather values for the static rating are 0.6 $\mathrm{m} / \mathrm{s}, 26{ }^{\circ} \mathrm{C}$, and $1000 \mathrm{~W} / \mathrm{m}^{2}$. The histograms of the measured weather magnitudes are shown in Figures 2, 3 and 4. Comparing the measured values with those of the static limit, $0.1 \%$ of the solar heating measurements, $3 \%$ of the air temperature measurements, and $42.4 \%$ of the wind speed measurements are unfavorable. Although the solar heating limit and the air temperature limit are conservative, the percentage of unfavorable wind speed measurements is large. 


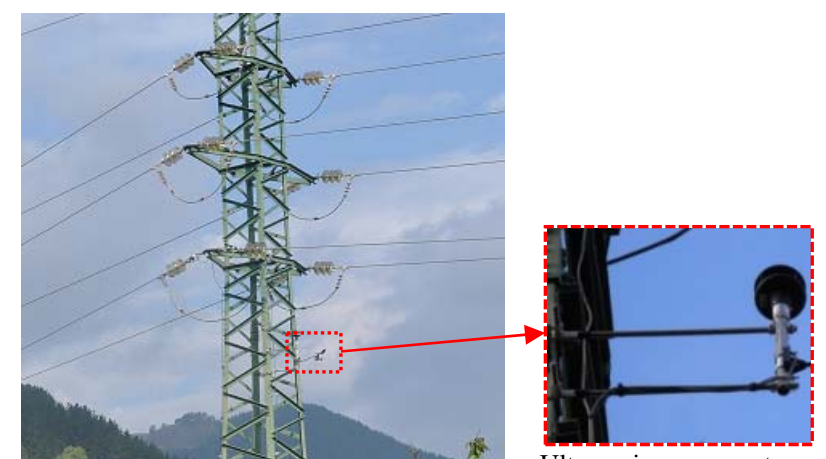

Ultrasonic anemometer

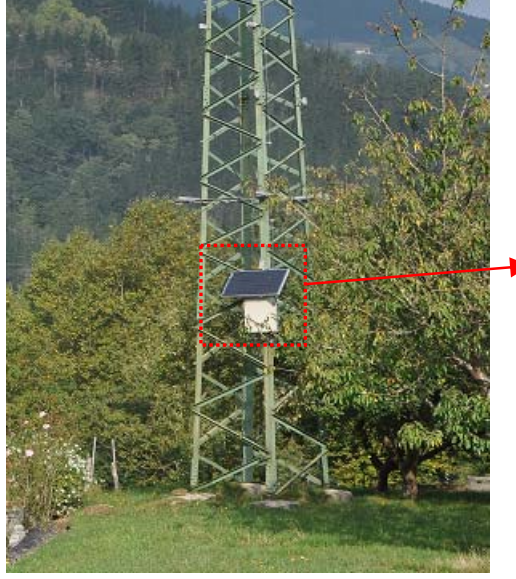

Fig.1. Monitoring system

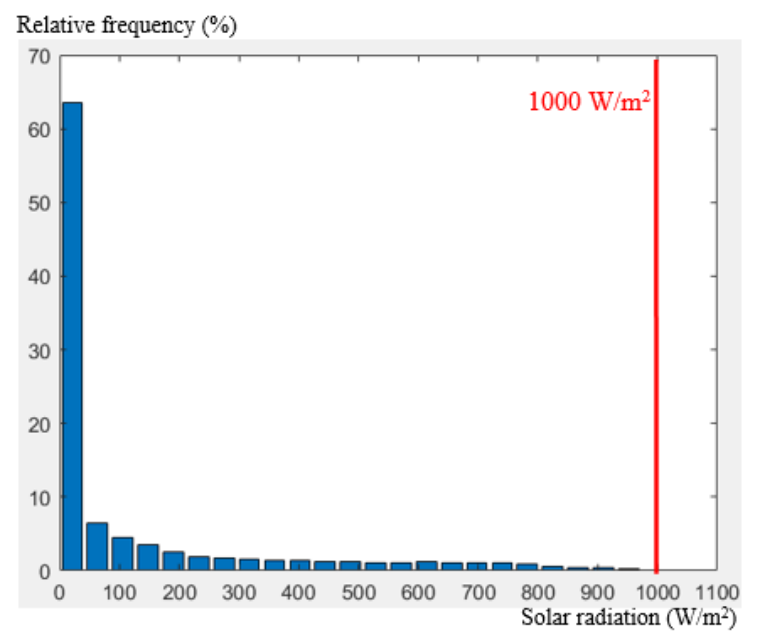

Fig.2. Histogram of the measured solar radiation

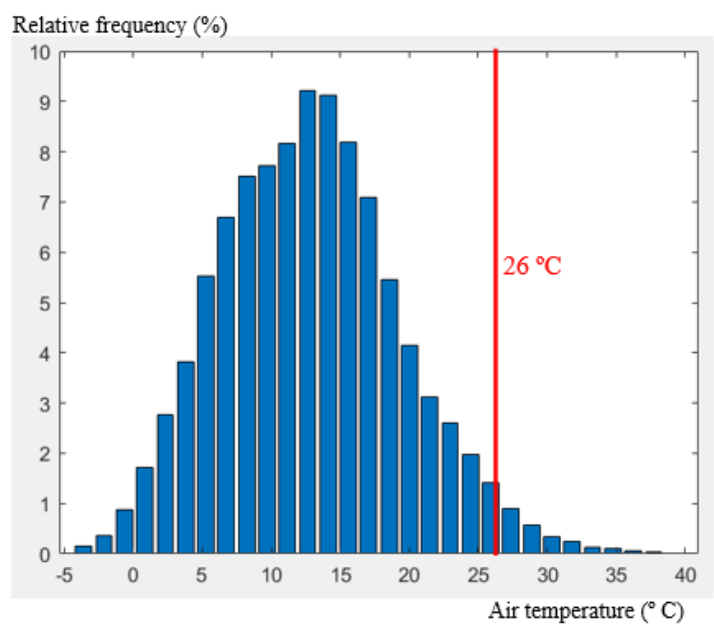

Fig.3. Histogram of the measured air temperature

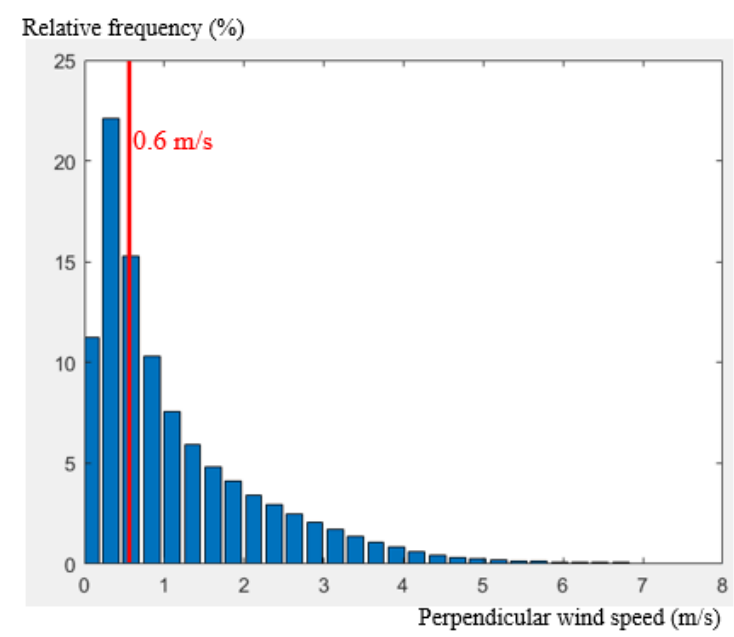

Fig.4. Histogram of the measured equivalent perpendicular wind speed

\section{Results for MACT $=50^{\circ} \mathrm{C}$}

The static rating for a MACT of $50{ }^{\circ} \mathrm{C}$ is $318 \mathrm{~A}$. As the actual weather conditions differ from the assumed conditions, the actual rating value differs from the static rating.

Figures 5, 6, and 7 show the histograms of the ampacity increase because of solar radiation, air temperature and wind speed respectively. The results show that the weather magnitudes differ not only in the percentage of unfavorable values, but in the magnitude of their effects. The favorable solar heating conditions increase the ampacity up to $18 \%$ at night when there is no solar radiation. The effect of the air temperature is larger: the ampacity decreases up to $30 \%$ with high air temperature and increases up to $60 \%$ with low air temperatures. The effect of the wind speed is the most important: the ampacity decreases up to $50 \%$ with no wind and increases up to $160 \%$ with high wind speed. 


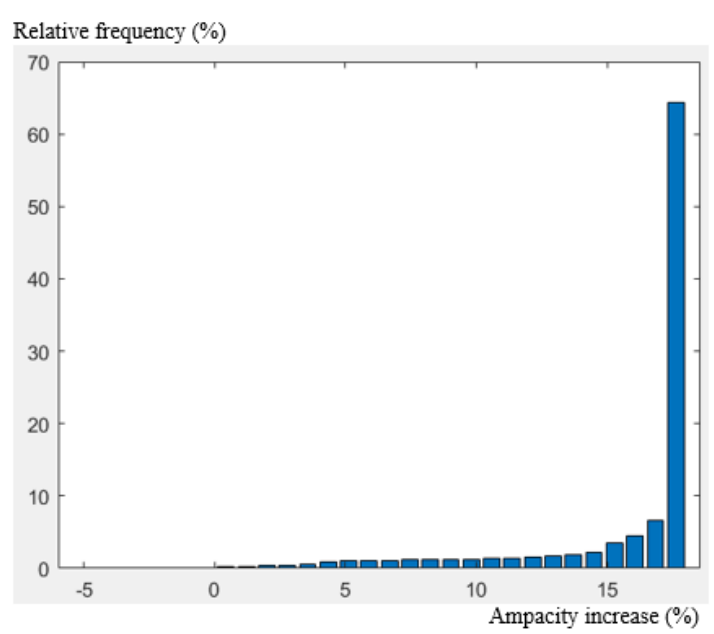

Fig.5. Histogram of the ampacity increase because of solar radiation

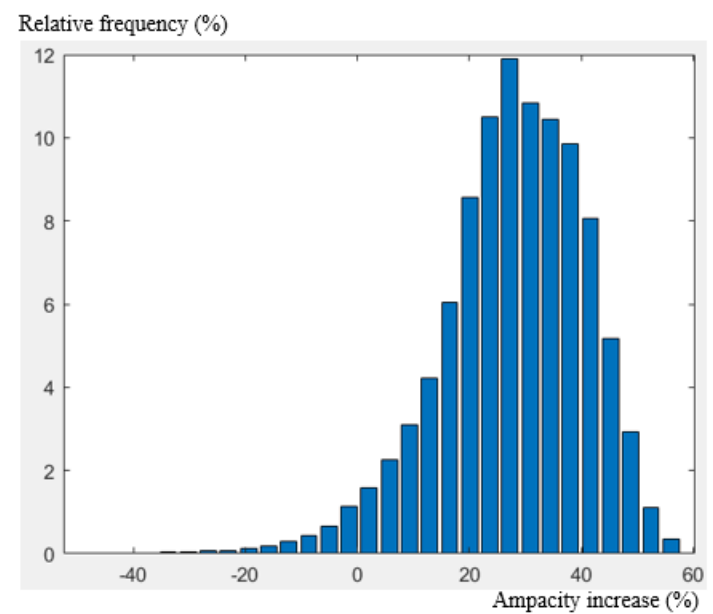

Fig.6. Histogram of the ampacity increase because of air temperature

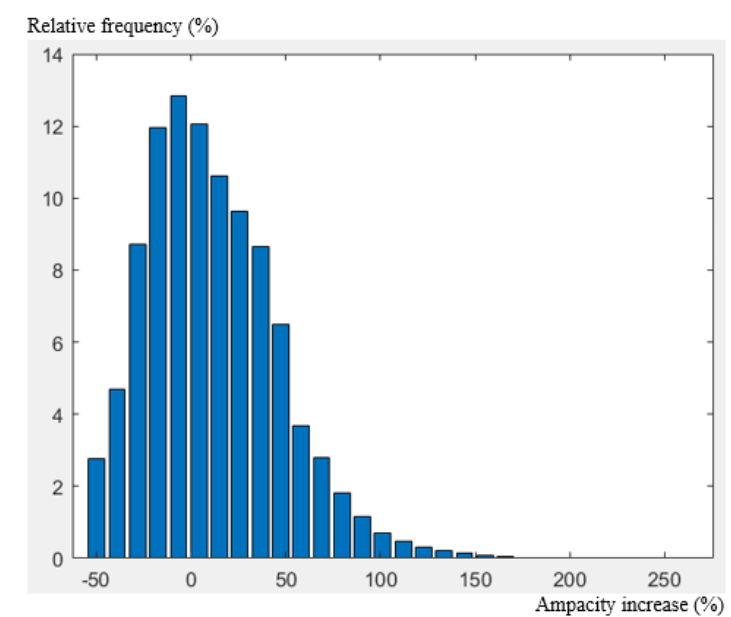

Fig.7. Histogram of the ampacity increase because of wind speed

The actual ampacity and the static ampacity have been compared. Fig. 8 shows the histogram of the ampacity increase represented as a percentage over the static ampacity. The percentage of unfavorable ampacity cases (actual ampacity lower than the static value) is $2.7 \%$. This value is much lower than the unfavorable wind speed percentage (42.4
$\%)$. This means that most of the unfavorable wind speed situations are compensated with favorable solar radiation and air temperature.

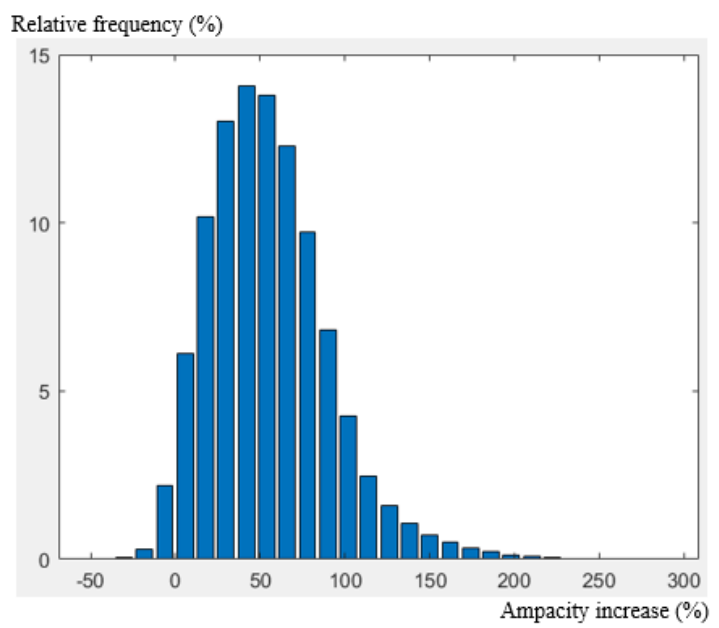

Fig.8. Histogram of the ampacity increase because of all weather magnitudes

An example of compensation is shown in Table I. The final ampacity is $363.3 \mathrm{~A}, 14.2 \%$ higher than the static value. Although the wind speed is low and results in an ampacity decrease, it is compensated by favorable solar radiation and air temperature.

TABLE I

Example of ampacity increase over the static ampacity with $\mathrm{MACT}=50^{\circ} \mathrm{C}$

\begin{tabular}{|c|c|c|}
\cline { 2 - 3 } \multicolumn{1}{c|}{} & Measured value & $\begin{array}{c}\text { Ampacity increase } \\
\text { over the static } \\
\text { ampacity (\%) }\end{array}$ \\
\hline $\begin{array}{c}\text { Solar } \\
\text { radiation }\end{array}$ & $0 \mathrm{~W} / \mathrm{m}^{2}$ & 18 \\
\hline $\begin{array}{c}\text { Air } \\
\text { temperature }\end{array}$ & $16.6^{\circ} \mathrm{C}$ & 20.8 \\
\hline Wind speed & $0.22 \mathrm{~m} / \mathrm{s}$ & -24.6 \\
\hline
\end{tabular}

Figure 9 shows the ampacity increase over the static limit because of wind speed on the $y$-axis, and the ampacity increase over the static limit because of the combined effect of solar heating and air temperature on the x-axis. In region $\mathrm{A}$ there is an increase of ampacity along both the x-axis and $y$ axis. $56.5 \%$ of situations over the total are in region $\mathrm{A}$ and are favorable. In region $\mathrm{B}$ ampacity decreases along both the $\mathrm{x}$-axis and $\mathrm{y}$-axis. $0.2 \%$ of situations are in region $\mathrm{B}$ and are unfavorable. In region C1 wind speed is unfavorable but is compensated by solar heating and air temperature, resulting in a favorable situation. $40 \%$ of situations are in C1. In region C2 wind speed is unfavorable, but although the solar heating and air temperature are favorable, the situation is unfavorable. $2.3 \%$ of the situations are in C2. In region D1 solar heating and air temperature are unfavorable but are compensated by wind speed, resulting in a favorable situation. $0.8 \%$ of the situations are in D1. In region D2 solar heating and air 
temperature are unfavorable but although the wind speed is favorable, the situation is unfavorable. $0.2 \%$ of the situations are in D2.

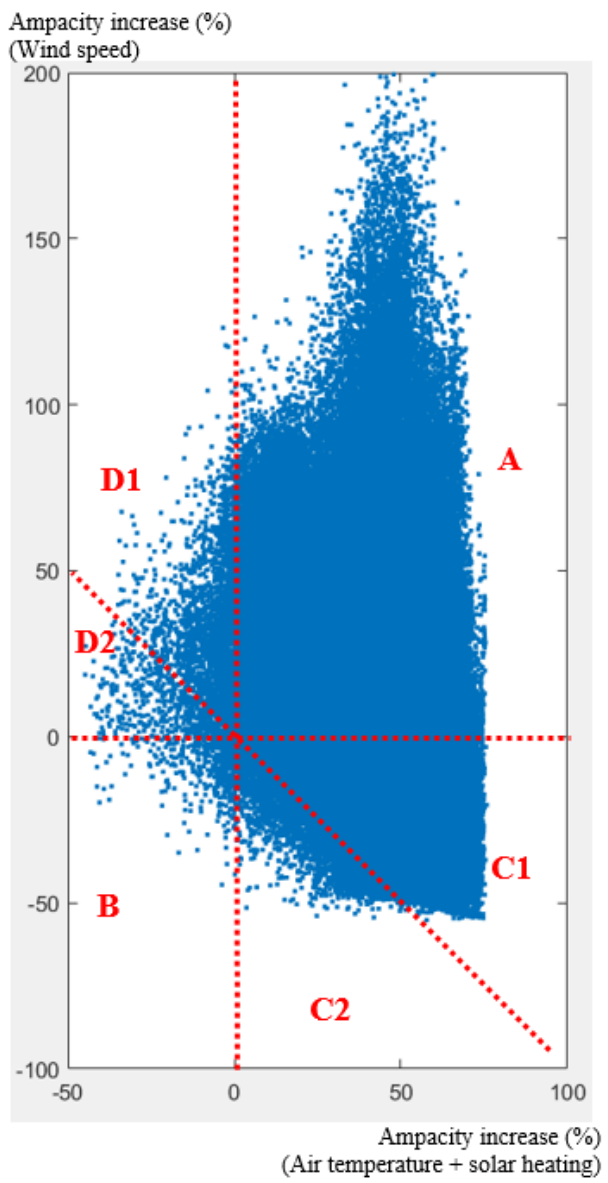

Fig.9. Ampacity variation at MACT $50{ }^{\circ} \mathrm{C}$. $\mathrm{x}$-axis: ampacity increase because of the combined effect of solar heating and air temperature. $y$-axis: ampacity increase because of wind speed

\section{Results for $M A C T=150^{\circ} \mathrm{C}$}

The static rating for a MACT of $150{ }^{\circ} \mathrm{C}$ is $744.4 \mathrm{~A}$. The rating is higher than for $50^{\circ} \mathrm{C}$. Similarly, all the terms of the thermal balance represented by (1) are larger than for $50{ }^{\circ} \mathrm{C}$. As the thermal balance terms are different, the effect of the weather magnitudes changes. The relative effect of the wind speed increases over the effect of the solar heating and air temperature. Table II shows the same situation analyzed in Table I but for $150{ }^{\circ} \mathrm{C}$. The final ampacity is $661.8 \mathrm{~A}, 11.1 \%$ smaller than the static value. In this case, the unfavorable wind speed is not compensated by the favorable solar and air temperature values. For $50{ }^{\circ} \mathrm{C}$, the ampacity increase owing to solar heating is $18 \%$ and for $150{ }^{\circ} \mathrm{C}$ it is reduced to $2.6 \%$. Similarly, the ampacity increase because of air temperature is reduced from $20.8 \%$ to $3.4 \%$.

Figure 10 is equivalent to Fig. 9 but for $150^{\circ} \mathrm{C}$. The axes limits have been maintained to see the difference. The points are concentrated in a smaller area. Therefore, the ampacity increase is smaller on both axes. However, the decrease is larger on x-axis, which corresponds to solar heating and air temperature.

TABLE II

Situation example of ampacity increase over the static ampacity with MACT $=150{ }^{\circ} \mathrm{C}$

\begin{tabular}{|c|c|c|}
\cline { 2 - 3 } \multicolumn{1}{c|}{} & Measured value & $\begin{array}{c}\text { Ampacity increase } \\
\text { over the static } \\
\text { ampacity (\%) }\end{array}$ \\
\hline $\begin{array}{c}\text { Solar } \\
\text { radiation }\end{array}$ & $0 \mathrm{~W} / \mathrm{m}^{2}$ & 2.6 \\
\hline $\begin{array}{c}\text { Air } \\
\text { temperature }\end{array}$ & $16.6^{\circ} \mathrm{C}$ & 3.4 \\
\hline Wind speed & $0.22 \mathrm{~m} / \mathrm{s}$ & -17.1 \\
\hline
\end{tabular}

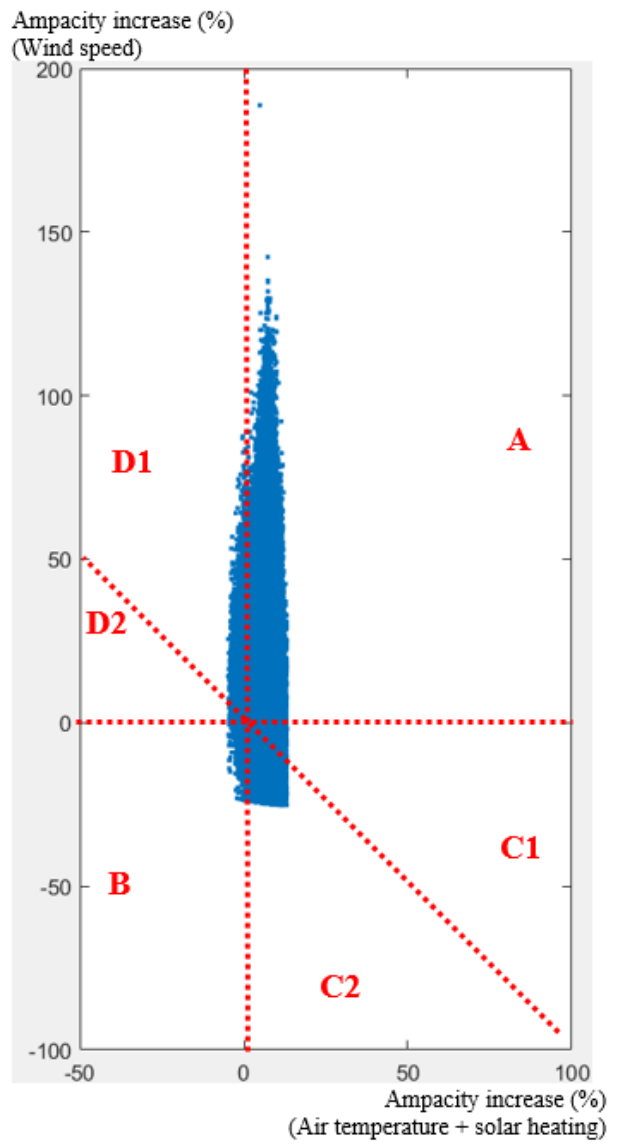

Fig.10. Ampacity variation at MACT $150{ }^{\circ} \mathrm{C}$. $\mathrm{x}$-axis: ampacity increase because of the combined effect of solar heating and air temperature. $y$-axis: ampacity increase because of wind speed

The percentage of situations for the different regions are shown in Table III for MACTs of $50{ }^{\circ} \mathrm{C}$ and $150{ }^{\circ} \mathrm{C}$ respectively. The value for regions $\mathrm{A}$ and $\mathrm{B}$ does not depend on the MACT. However, the distribution between C1 and C2 changes. The compensation effect of solar heating and air temperature is reduced and as a result, there is a transfer of situations from C1 (compensated situation) to C2 (uncompensated situation). The transfer from $\mathrm{C} 1$ to $\mathrm{C} 2$ is negative, because the unfavorable situations are more. Similarly, it also changes the distribution between D1 and D2. In this case, there is a transfer of situations from D2 
(uncompensated situation) to D1 (compensated situation) because it is the wind speed that makes the compensation. The transfer from D2 to D1 is positive, because the number of favorable situations has increased. However, the number of situations in $\mathrm{C} 1+\mathrm{C} 2$ is higher than the situations in $\mathrm{D} 1+\mathrm{D} 2$ and thus, the number of unfavorable situations increase from $2.5 \%\left(50{ }^{\circ} \mathrm{C}\right)$ to $29.2 \%\left(150^{\circ} \mathrm{C}\right)$.

TABLE III

Distribution of situations with MACT $=50{ }^{\circ} \mathrm{C}$ and $150{ }^{\circ} \mathrm{C}$

\begin{tabular}{|c|c|c|c|}
\hline Region & $\begin{array}{c}\text { Percentage of } \\
\text { situations } \\
\text { MACT } \mathbf{5 0}^{\mathbf{}} \mathbf{C}\end{array}$ & $\begin{array}{c}\text { Percentage of } \\
\text { situations } \\
\text { MACT }=\mathbf{1 5 0}^{\mathbf{}} \mathbf{C}\end{array}$ & $\begin{array}{c}\text { Favorable } \\
\text { /unfavorable }\end{array}$ \\
\hline A & 56.5 & 56.5 & Favorable \\
\hline B & 0.2 & 0.2 & Unfavorable \\
\hline C1 & 40 & 13.3 & Favorable \\
\hline C2 & 2.3 & 29 & Unfavorable \\
\hline D1 & 0.8 & 1 & Favorable \\
\hline D2 & 0.2 & 0 & Unfavorable \\
\hline
\end{tabular}

\section{ADAPTIVE STATIC LINE RATING}

A constant weather assumption for the static rating results in more unfavorable situations for higher MACTs. Therefore, to maintain the same level of unfavorable situations the assumptions must change. For example, to reduce the unfavorable situations from $29.2 \%$ to $2.5 \%$ at $150{ }^{\circ} \mathrm{C}$, the wind speed assumption should change from $0.6 \mathrm{~m} / \mathrm{s}$ to 0.223 $\mathrm{m} / \mathrm{s}$ for the pilot line.

\section{A. Method proposed for the adaptive static line rating}

An adaptive SLR for system operation is proposed based on the variation of the wind speed limit with the MACT. The solar heating and air temperature assumptions are maintained constant. The wind speed is chosen because it is the magnitude with the largest effect on ampacity.

In [6], the authors define some indicators of the security of line ratings. Indicators such as security confidence level, maximum temperature exceedance, and temperature increase in the worst $1 \%$ cases, are applied to several line rating forecasting methods. For the adaptive SLR, the security confidence level is chosen as the reference indicator. The security confidence level measures the percentage of situations where the forecasted rating is below the measured rating. The wind speed limit is selected so that the security confidence level is identical in all the MACT ranges.

\section{B. Results obtained in the pilot line}

Table IV shows the wind speed limits for several MACTs for a security confidence level of $97.5 \%$ (2.5 \% of unfavorable situations). These values are represented in Fig. 11.
TABLE IV

Wind speed assumption as a function of MACT for a security confidence level of $97.5 \%$

\begin{tabular}{|c|c|}
\hline MACT $\left({ }^{\mathbf{}} \mathbf{C}\right)$ & $\begin{array}{c}\text { Wind speed } \\
(\mathbf{m} / \mathbf{s})\end{array}$ \\
\hline 50 & 0.6 \\
\hline 75 & 0.323 \\
\hline 100 & 0.254 \\
\hline 125 & 0.23 \\
\hline 150 & 0.223 \\
\hline
\end{tabular}

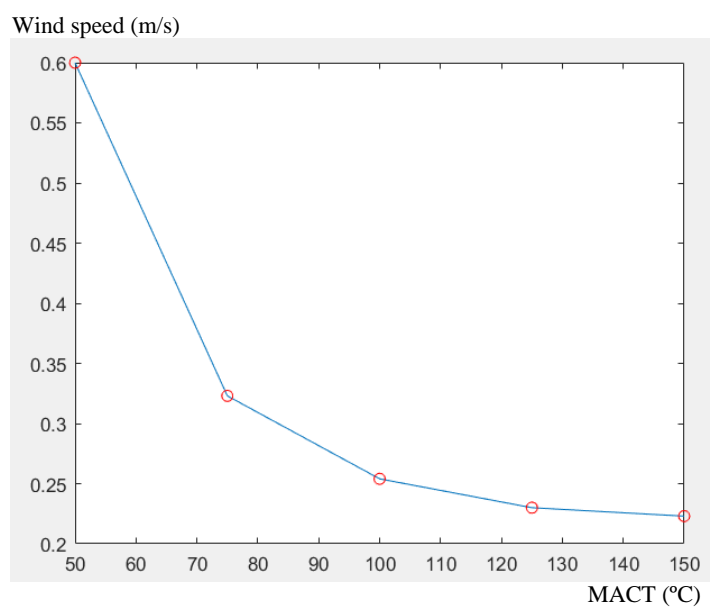

Fig.11. Wind speed assumption as a function of MACT for a security confidence level of $97.5 \%$

The adaptive static rating improves the security for high MACTs, but the ampacity is reduced. For example, for 150 ${ }^{\circ} \mathrm{C}$, the adaptive static rating results in an ampacity reduction from $744.4 \mathrm{~A}$ to $619.2 \mathrm{~A}$. This means a reduction of the rating by $17 \%$. Table $\mathrm{V}$ and Fig. 12 show the static rating and the proposed adaptive static rating.

TABLE V

Wind speed assumption as a function of MACT for a security confidence level of $97.5 \%$

\begin{tabular}{|c|c|c|c|}
\hline MACT $\left({ }^{\circ} \mathbf{C}\right)$ & $\begin{array}{c}\text { Static } \\
\text { rating (A) } \\
\mathbf{0 . 6 ~} \mathbf{~ m} / \mathbf{s}\end{array}$ & $\begin{array}{c}\text { Adaptive } \\
\text { static rating } \\
\text { (A) }\end{array}$ & $\begin{array}{c}\text { Rating } \\
\text { reduction } \\
\mathbf{( \% )}\end{array}$ \\
\hline 50 & 318.1 & 318.1 & 0 \\
\hline 75 & 482.3 & 418.9 & 13.1 \\
\hline 100 & 591.2 & 494.6 & 16.3 \\
\hline 125 & 675.1 & 559.9 & 17.1 \\
\hline 150 & 744.4 & 619.2 & 16.8 \\
\hline
\end{tabular}




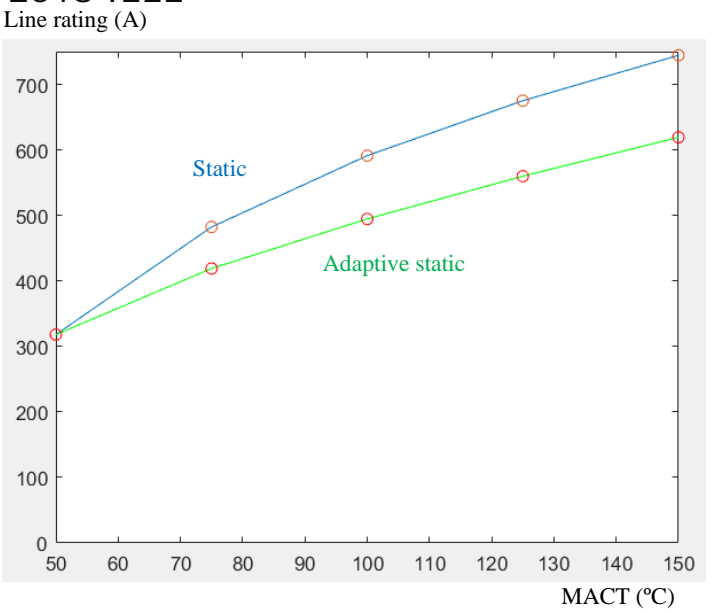

Fig.12. Line rating reduction for the adaptive static line rating

\section{CONCLUSION}

The weather magnitude assumptions of the static rating have been analyzed separately. The main conclusion is that part of the success of the static rating is because of the compensation between weather parameters in mixed situations. Success means that the static rating is safe because it is lower than the actual limit. A mixed situation is when some weather magnitudes are favorable and the remaining ones are unfavorable. The most common mixed situations are those with unfavorable wind speed and favorable air temperature and solar heating. For the pilot line, $42.3 \%$ of the cases meet these conditions.

A mixed situation can be favorable or unfavorable depending on the relative effect of the weather magnitudes. An important finding of the analysis is that the relative effect changes with the MACT. For high MACTs the compensation effect of the favorable air temperature and solar heating is lower and therefore a larger percentage of the mixed situations are unfavorable. For the pilot line, for a MACT of $50{ }^{\circ} \mathrm{C}, 94.6 \%$ of cases with unfavorable wind speed, favorable air temperature and solar heating result in a favorable condition, whereas for a MACT of $150{ }^{\circ} \mathrm{C}$, only $31.4 \%$ are favorable.

Therefore, the application of the same weather assumptions regardless of the MACT results in higher risk for conductors with high MACT. This is the case of HTLS conductors with a MACT well above $100{ }^{\circ} \mathrm{C}$. Fortunately, at high temperatures, HTLS conductors work above the kneepoint temperature, and the coefficient of thermal expansion (CTE) is low. Therefore, when the MACT is limited by clearance, the clearance violation because of temperature exceedance is lower than for conventional conductors with higher CTE values. However, this is not the case when the MACT is limited by annealing.

As a result, an adaptive SLR for system operation and planning is proposed, based on a variation of the wind speed limit with the MACT. The value of the wind speed assumption decreases as the MACT increases. In the case of the pilot line, the wind speed assumption is $0.6 \mathrm{~m} / \mathrm{s}$ for $50{ }^{\circ} \mathrm{C}$ MACT, but it decreases to $0.223 \mathrm{~m} / \mathrm{s}$ for $150^{\circ} \mathrm{C}$ MACT. The security increase of the method is related to a decrease on the line rating. For $150{ }^{\circ} \mathrm{C}$ MACT, the rating reduction is $16.8 \%$.

\section{ACKNOWLEDGMENT}

The authors would like to thank Iberdrola utility for the help extended for the achievement of this project.

\section{REFERENCES}

[1] CIGRE Brochure (Ref. No. 498): "Guide for application of direct realtime monitoring systems,” 2012.

[2] E. Fernandez, I. Albizu, M. T. Bedialauneta, A. J. Mazon, and P. T. Leite, "Review of dynamic line rating systems for wind power integration,” Renew. Sustain. Energy Rev., vol. 53, pp. 80-92, 2016.

[3] E. Cloet, J. L. Lilien, and P. Ferrieres, "Experiences of the Belgian and French TSOs using the "Ampacimon" real-time dynamic rating system,” in Proc. CIGRE Meeting, Paper C2-106, Paris, 2010.

[4] A. Arroyo, P. Castro, M. Manana, R. Domingo, and A. Laso, " $\mathrm{CO}_{2}$ footprint reduction and efficiency increase using the dynamic rate in overhead power lines connected to wind farms", Applied Thermal Engineering, vol. 130, pp. 1156-1162, 2018.

[5] A. Michiorri, H. M. Nguyen, S. Alessandrini, J. B. Bremnes, S. Dierer, E. Ferrero, B.-E. Nygaard, P. Pinson, N. Thomaidis, and S. Uski, "Forecasting for dynamic line rating," Renew. Sustain. Energy Rev., vol. 52, pp. 1713-1730, 2015.

[6] I. Albizu, E. Fernandez, A. J. Mazon, and R. Alberdi, "Forecast ratio and security analysis of rating forecasting methods in an overhead line," IET Generation, Transmission \& Distribution, vol. 11, no. 6, pp. 15981604, 2017.

[7] F. R. McElvain, and S. S. Mulnix, "Statistically Determined Static Thermal Ratings of Overhead High Voltage Transmission Lines in the Rocky Mountain Region,” IEEE Trans. Power Syst., vol. 15, no. 2, pp. 899-902, 2000.

[8] J. Heckenbergerová, P. Musilek, and K. Filimonenkov, "Quantification of gains and risks of static thermal rating based on typical meteorological year," Int. Journal of Electrical Power \& Energy Systems, vol. 44, no. 1, pp. 227-235, 2013.

[9] CIGRE Brochure (Ref. No. 299): 'Guide for selection of weather parameters for bare overhead conductor ratings', 2006.

[10] A. Gómez, J. Riquelme, and P. Cruz, "Planning and Operational Issues Arising From the Widespread Use of HTLS Conductors," IEEE Trans. Power Syst., vol. 22, no. 4, pp. 1446-1455, 2007.

[11] K. Kopsidas, and S. M. Rowland, "Evaluating opportunities for increasing power capacity of existing overhead line systems," IET Generation, Transmission \& Distribution, vol. 5, no. 1, pp. 1-10, 2011.

[12] A. Tokombayev, and G. T. Heydt, "High Temperature Low Sag Upgrades and Payback for the Economic Operation Improvement of Power Transmission Systems", Electric Power Components and Systems, vol. 43, no. 3, pp. 345-355, 2015.

[13] S. Nuchprayoon, A. Chaichana, "Cost evaluation of current uprating of overhead transmission lines using ACSR and HTLS conductors," in Proc. IEEE International Conference on Environment and Electrical Engineering (EEEIC), Milan. Italy, 2017.

[14] S. Favuzza, M.G. Ippolito, F. Massaro, G. Paterno, A. Puccio, G. Filippone, "A new approach to increase the integration of RES in a mediterranean island by using HTLS conductors," in Proc. International Conference on Power Engineering, Energy and Electrical Drives (POWERENG), Riga, Latvia, 2015.

[15] D. Douglass et al., "Real-Time Overhead Transmission Line Monitoring for Dynamic Rating," IEEE Trans. Power Del., vol. 31, no. 3, pp. 921-927, 2016.

[16] IEEE Standard for Calculating the Current-Temperature Relationship of Bare Overhead Conductors, IEEE Standard 738, 2013.

[17] CIGRE Brochure (Ref. No. 601): "Guide for thermal rating calculations of overhead lines," 2014.

[18] N. P. Schmidt, "Comparison Between IEEE and CIGRE Ampacity Standards,” IEEE Trans. Power Del., vol. 14, no. 4, pp. 1555- 1562, 1999.

[19] A. Arroyo, P. Castro, R. Martinez, M. Manana, A. Madrazo, R. Lecuna and A. Gonzalez, "Comparison between IEEE and CIGRE Thermal 
Behaviour Standards and Measured Temperature on a 132-kV Overhead Power Line,” Energies, vol. 8, no. 12, pp. 13660-13671, 2015.

[20] P. Castro, A. Arroyo, R. Martinez, M. Manana, R. Domingo, A. Laso, and R. Lecuna, "Study of different mathematical approaches in determining the dynamic rating of overhead power lines and a comparison with real time monitoring data," Applied Thermal Engineering, vol. 111, pp. 95-102, 2017.

[21] M. Isozaki, H. Haji, K. Nagano, and N. Iwama, "Verification of forced convective cooling from overhead conductors in low velocity by wind tunnel testing”, IEEJ Trans. on Power and Energy, vol. 121, no. 6, pp. 782-788, 2001.

[22] S. L. Chen, W.Z. Black and H.W. Loard, "High-Temperature Ampacity Model for Overhead Conductors”, IEEE Trans. Power Del., vol. 17, no. 4, pp. 1136-1141, 2002.

[23] L. Kotni, "A proposed algorithm for an overhead transmission line conductor temperature rise calculation,” International Transactions on Electrical Energy Systems, vol. 24, no. 4, pp. 578-596, 2014.

[24] J. Rodriguez, and C.M. Franck, "Radial Thermal Conductivity of allAluminum Alloy Conductors”, IEEE Trans. Power Del., vol. 30, no. 4, pp. 1983-1990, 2015.

\section{BIOGRAPHIES}

Igor Albizu (M'12) was born in Zumaia, Spain. He received the M.Sc. degree in Electronic Instrumentation Systems from the University of Manchester, Manchester, U.K., in 1999, and the Ph.D. degree from the University of the Basque Country UPV/EHU, Bilbao, Spain, in 2008. Currently, he is a Lecturer with the Electrical Engineering Department, Gipuzkoa Faculty of Engineering, University of the Basque Country UPV/EHU. His research activities are concentrated in the area of transmission-line thermal rating.

Elvira Fernández (M’12) was born in Bilbao, Spain. She received her Ph.D. degree from the University of the Basque Country UPV/EHU, Bilbao, Spain, in 2008. Currently, she is a Lecturer with the Electrical Engineering Department, Faculty of Engineering of Bilbao, University of the Basque Country UPV/EHU. Her research activities are concentrated in the area of transmission-line thermal rating.

Rafael Alberdi was born in La Coruña, Spain. He received his M.Sc. degree in Energy and Power Electronics from Mondragon University, Spain, in 2013. He is currently pursuing his Ph.D. degree on Prediction of ampacity with the Electrical Engineering Department, Faculty of Engineering of Bilbao, Spain, University of the Basque Country UPV/EHU.

Miren Terese Bedialauneta was born in Ondarroa, Spain. She received her Ph.D. degree from the University of the Basque Country UPV/EHU, Bilbao, Spain, in 2017. Currently, she is a Lecturer with the Electrical Engineering Department, Faculty of Engineering of Bilbao, University of the Basque Country UPV/EHU. Her research activities are concentrated in the area of transmission-line thermal rating.

Angel Javier Mazón (M’03) was born in Bilbao, Spain. He received the Ph.D. degree from the University of the Basque Country UPV/EHU, Bilbao, Spain, in 1994. In 1992, he was with Labein Research Laboratories. Currently, he is a Full-Time Professor in the Electrical Engineering Department, Faculty of Engineering of Bilbao. His research activities are concentrated in the area of electric power systems, transient simulation, fault analysis, and transmission-line thermal rating. 